\title{
Cloning, pharmacological characterization, and expression analysis of Atlantic salmon (Salmo salar L.) nuclear progesterone receptor
}

\author{
Shi X Chen ${ }^{1,3}$, Jan Bogerd ${ }^{1}$, Eva Andersson ${ }^{2}$, Fernanda F L Almeida ${ }^{1,4}$, Geir Lasse Taranger $^{2}$ \\ and Rüdiger W Schulz ${ }^{1,2}$ \\ ${ }^{1}$ Department of Biology, Faculty of Science, Utrecht University, Padualaan 8, 3584 CH Utrecht, The Netherlands, \\ ${ }^{2}$ Research Group Reproduction and Growth, Institute of Marine Research, PO Box 1870 Nordnes, 5817 Bergen, \\ Norway, ${ }^{3}$ State Key Laboratory of Marine Environmental Science, Xiamen University, Xiamen 361005, People's \\ Republic of China and ${ }^{4}$ Embrapa Amazônia Ocidental, Rodovia AM-10, Km 29 PO Box 319, 69010-97, Manaus, \\ Brazil
}

Correspondence should be addressed to R W Schulz at Department of Biology, Faculty of Science, Utrecht University; Email: r.w.schulz@uu.nl

\begin{abstract}
To better understand the role(s) of progestogens during early stages of spermatogenesis, we carried out studies on the nuclear progesterone receptor (Pgr) of the Atlantic salmon. Its open-reading frame shows the highest similarity with other piscine Pgr proteins. When expressed in mammalian cells, salmon Pgr exhibited progestogen-specific, dose-dependent induction of reporter gene expression, with $17 \alpha, 20 \beta$-dihydroxy-4-pregnen-3-one (DHP) showing the highest potency. We then analyzed testicular pgr mRNA and DHP plasma levels in animals during the onset of spermatogenesis, which were exposed to natural light or to constant light, to induce significant differences in testis growth. Grouping of the animals according to their progress through spermatogenesis showed that testicular pgr mRNA levels as well as DHP plasma levels first increased when germ cells had reached the stage of late type B spermatogonia and further increased when entered meiosis, i.e. when spermatocytes were present. However, in situ hybridization studies revealed that pgr mRNA expression was restricted to Sertoli cells, with a strong signal in Sertoli cells contacting type A/early type B spermatogonia, while Sertoli cells contacting larger germ cell clones with further differentiated stages (e.g. late type B spermatogonia) were less intensely/not stained. We conclude that the increase in pgr mRNA levels per pair of testis reflects, at least in part, the increased number of Sertoli cells enveloping type A and early type B spermatogonia. We propose that Sertoli cell-expressed Pgr may mediate DHP-stimulated early steps in spermatogenesis in Atlantic salmon, such as an increase in the number of new spermatogonial cysts.

Reproduction (2011) 141 491-500
\end{abstract}

\section{Introduction}

Spermatogenesis is a cellular developmental process divided into three major phases: the spermatogonial phase with different generations of spermatogonia; the meiotic phase with primary and secondary spermatocytes; and the spermiogenic phase with haploid spermatids and spermatozoa (Schulz et al. 2010). Vertebrate spermatogenesis is controlled by the coordinated action of a range of hormones and growth factors. In teleost fish, also sex steroids of the progestin family, such as $17 \alpha, 20 \beta$-dihydroxy-4-pregnen-3-one (DHP) or 17 $\alpha, 20 \beta, 21$-trihydroxy-4-pregnen-3-one (20ß-S), play important roles during spermatogenesis. For example, they induce spermiation (Ueda et al. 1985), increase milt production (Baynes \& Scott 1985), and stimulate spermatozoa motility (Miura et al. 1992, Tubbs \& Thomas 2008).
In salmonid fish, there are two peaks of DHP plasma levels during their reproductive cycle. The quantitatively more important peak is observed in the spawning season, while a smaller and transient increase is reported during the progression of spermatogonial proliferation (Dépéche \& Sire 1982, Scott \& Sumpter 1989, Vizziano et al. 1996), suggesting that DHP plays a role not only during spermiation and spawning but also during early stages of spermatogenesis. Indeed, DHP induced the initiation of meiosis in male germ cells in Japanese eel (Anguilla japonica; Miura et al. 2006).

The biological activity of progestogens is mediated via specific receptors. Nuclear and membrane-bound progestogen receptor types are highly expressed in fish testis (Ikeuchi et al. 2002, Hanna \& Zhu 2009). Recent results suggest that membrane-associated progestin receptor $\alpha$ $(\mathrm{mPR} \alpha)$ mediates the non-genomic actions of progestins 
to induce sperm hypermotility in a number of teleost species (Tubbs \& Thomas 2008). In Japanese eel, progesterone receptor 1 (pgr1) mRNA was expressed in germ cells, Sertoli cells, and interstitial cells of testis, whereas pgr2 mRNA was detected only in germ cells (Miura et al. 2006). In our previous work on zebrafish (Danio rerio), we found that pgr mRNA was expressed in Leydig and Sertoli cells (Chen et al. 2010). However, other data indicated that Pgr protein can be detected in germ cells (Hanna et al. 2010). Taken together, these data open the possibility that the Pgr may be involved in mediating DHP effects on early stages of spermatogenesis in teleost fish.

To broaden the data basis as regards the role of Pgr in fish spermatogenesis from eel (Anguilliformes) and zebrafish (Cypriniformes) to a third unrelated order, the Salmoniformes, we isolated a full-length pgrcDNA from Atlantic salmon (Salmo salar L.) and characterized pharmacologically the salmon Pgr. To investigate the possible role of Pgr during the spermatogonial proliferation phase, we determined the cellular localization of the pgr mRNA in salmon testis by in situ hybridization. Finally, making use of the fact that the onset of puberty in Atlantic salmon is sensitive to photoperiod manipulation, we analyzed changes in testicular pgr mRNA levels, plasma DHP concentrations, and testis histology during early spermatogenesis in fish exposed to photoperiod conditions that stimulated or inhibited the onset of pubertal testis growth.

\section{Results}

\section{Isolation and sequence analysis of salmon pgr cDNA}

The open-reading frame (ORF) of the salmon $p g r$ consisted of 2157 nucleotides (GenBank accession number: GU583841), encoding a protein of 718 amino acids (Supplementary Figure 2, see section on supplementary data given at the end of this article). Comparison of the deduced amino acid sequence of the salmon pgr with PGRs from other species is shown in Supplementary Table 2 (see section on supplementary data given at the end of this article). The salmon Pgr amino acid sequence could be subdivided into four domains. An $\mathrm{N}$-terminal transactivation domain (TAD) showed low homology (10.5-26.7\%), while the putative DNA-binding domain (DBD) and ligand-binding domain (LBD) showed high homology (DBD, 83.3-97.2\%; LBD, 64.7-85.3\%), with PGRs of other vertebrates. The overall homology of salmon Pgr with PGRs from other species is 37.0-62.9\%. A phylogenetic tree, constructed from the aligned amino acid sequences using the neighbor-joining method, revealed that the known PGRs are divided into three major clades (Supplementary Figure 3, see section on supplementary data given at the end of this article). The first clade consisted of fish Pgrs, the second clade contained avian, reptilian, and amphibian PGRs, and the last clade contained mammalian PGRs.

\section{Steroid-specific transactivation of the salmon Pgr}

To determine the steroid-dependent transactivation properties of the salmon Pgr, HEK 293T cells, which do not display endogenous PGR activity (Chen et al. 2010), were transfected with the pGL3-MMTV-Luc reporter construct alone or together with the salmon $p g r$ expression vector construct. Next, transfected cells were stimulated with increasing concentrations of different steroid hormones. Dose-dependent, Pgrmediated activation of the MMTV promoter was clearly shown for DHP and 20ß-S (Fig. 1A), the one with the lowest $\mathrm{EC}_{50}$ value being DHP $(17.9 \pm 0.2 \mathrm{nM})$. Also at a fixed concentration of $1 \mu \mathrm{M}, \mathrm{DHP}$ and $20 \beta$-S were the most potent inducers of luciferase activity (four- and twofold above control respectively; Fig. 1B). The other three progesterone-related hormones tested elicited increases in luciferase activity only at a concentration of $10 \mu \mathrm{M}$, while other steroid hormones assayed (testosterone, 11-ketotestosterone (11-KT), 17 $\beta$-estradiol $\left(E_{2}\right)$, or cortisol) were ineffective at $10 \mu \mathrm{M}$.
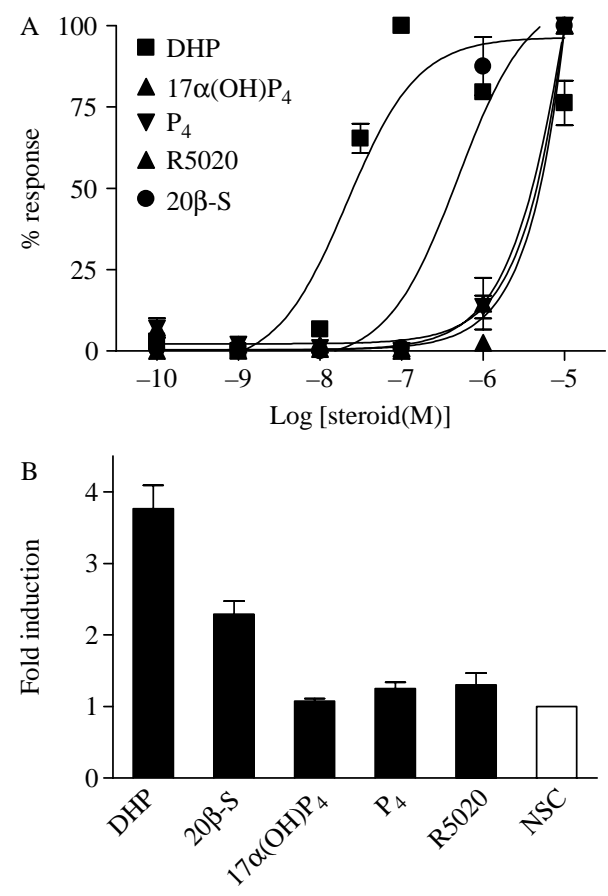

Figure 1 Ligand-induced transactivation properties of the Atlantic salmon Pgr. HEK 293T cells were transiently co-transfected with the pGL3-MMTV-Luc and the salmon pgr expression vector constructs. (A) Transfected cells were incubated with increasing concentrations (from $0.1 \mathrm{nM}$ to $10 \mu \mathrm{M}$ ) of various progesterones. Percentage (\%) of response: values are given relative to the maximal amount of luciferase activity for each condition. Each point represents the mean \pm s.E.M. of three independent experiments, with duplicates for each steroid concentration. Curves were generated using non-linear regression (GraphPad Prism 4.0). (B) Transfected cells were incubated with or without $1 \mu \mathrm{M}$ of the steroids indicated. Data are expressed as the ratio of steroid:NSC (no steroid control). Each column represents the mean of three independent experiments, with the vertical bar representing the S.E.M. 


\section{Tissue distribution of salmon pgr mRNA}

Real-time, quantitative PCR analysis of several tissues from immature animals showed that testicular tissue had the highest levels of pgr expression, followed by ovarian tissue. Some pgr mRNA expression was also found in the pituitary and spleen, while pgr mRNA levels were very low or undetectable in the other tissues tested (Fig. 2).

\section{Cellular localization of pgr expression in salmon testis}

Identification of cell types expressing salmon pgr mRNA in the testis at the onset of spermatogenesis was accomplished by in situ hybridization using testis cryosections. A strong signal was observed in particular in the perinuclear area of Sertoli cells surrounding early generations of spermatogonia (Fig. 3A and B). No signal was observed when adjacent sections were hybridized with the sense cRNA pgr probe (inset Fig. 3B). Sertoli cells surrounding type $A$ and early type $B$ spermatogonia were more intensely labeled than Sertoli cells associated with further developed germ cell types (Fig. 3C and D).

\section{Effect of constant light on gonadosomatic index and testis histology}

All males kept under natural light (NL) conditions were recruited into maturation during the first half of the year. Hence, immature males with low gonadosomatic index (GSI) values and only type A spermatogonia were no longer found after 19 March (Supplementary Figure 4,

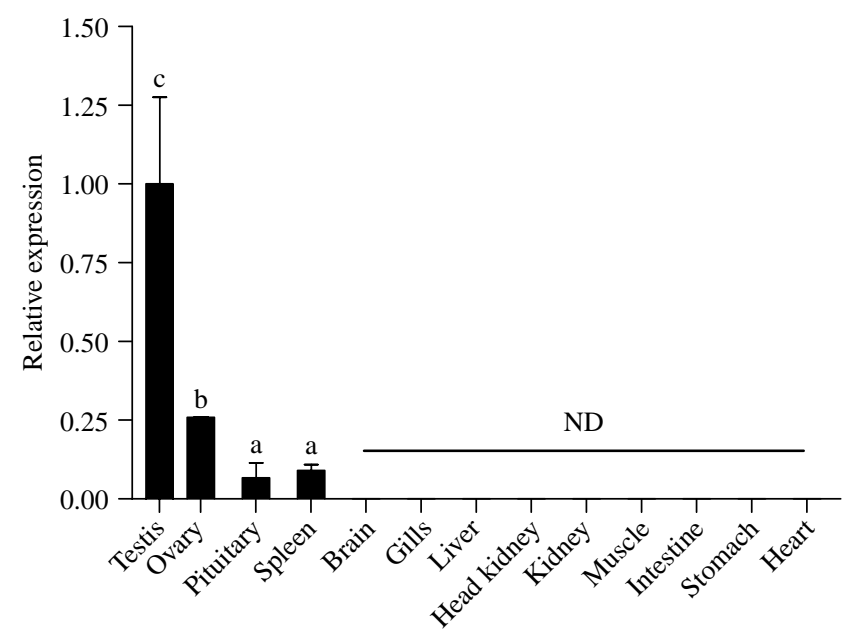

Figure 2 Relative expression of pgr mRNA in immature testis and in different tissues of immature female Atlantic salmon. The pgr mRNA expression levels were normalized to the expression of ef $1 \alpha$ mRNA. Values represent mean \pm S.E.M. $(n=3)$ relative to testicular $p g r$ mRNA levels. Tissues were collected at the beginning of December with GSI values below $0.05 \%$ in males and below $0.2 \%$ in females, as is typical for testes containing early spermatogonia, and typical for ovaries containing previtellogenic oocytes. Bars marked with different letters are significantly different from each other $(P<0.05)$. ND, not detectable. see section on supplementary data given at the end of this article). Males with testes showing early type B spermatogonia or late type B spermatogonia as the most advanced germ cell type were found on 18 February or 19 March and 25 April respectively, while spermatocytes were found in all males sampled on 11 June (Supplementary Figure 4). When sorted according to the most advanced stage of germ cell development, irrespective of the time of sampling, GSI values increased significantly with the progress in spermatogenesis (Fig. 4A; left of dashed line).

There were two main effects of exposure to constant light (LL). First, immature males showing only type A spermatogonia and low GSI values were found on all sampling dates, indicating that entry into maturation was blocked by exposure to LL for these fish, constituting $\sim 40 \%$ of the LL-exposed males (Supplementary Figure 4). Second, in males maturing under LL conditions ( $\sim 60 \%$ of LL-exposed males), testis growth exceeded the one found under NL conditions once the rapid growth phase had started after the sampling in April (Fig. 4A and B; Supplementary Figure 4). A comparison of GSI values between animals sampled in February and March showing early and late type B spermatogonia respectively revealed that irrespective of the light conditions, the first increase in GSI values was associated with the appearance of late type B spermatogonia (Fig. 4A and B; right of dashed line).

\section{Analysis of plasma DHP levels and testicular pgr mRNA expression in relation to testis histology}

When NL-exposed animals were grouped according to the stage of germ cell development, the DHP plasma levels were low when only type A spermatogonia were present in the testis but increased with progressing spermatogenesis (Fig. 4C). Comparing DHP levels in animals sampled in February or March that presented early or late type B spermatogonia respectively showed that the first increase in plasma DHP level was associated with the appearance of late type B spermatogonia (Fig. 4C, right of dashed line). A further increase was observed when spermatocytes were found in the testes (Fig. 4C and D; left of dashed line).

First, we calculated testicular pgr expression levels after normalization to elongation factor $1 \alpha($ ef $1 \alpha)$ mRNA levels but without applying corrections for testis or body size changes (Fig. 4E and F). In animals exposed to NL conditions, pgr mRNA levels were stable in testes containing type $\mathrm{A}$ and type $\mathrm{B}$ spermatogonia but decreased when meiosis had started (Fig. 4E; left of dashed line). Different from plasma DHP and GSI values, pgrexpression did not differ between animals sampled in February and March showing early and late type B spermatogonia respectively (Fig. 4E; right of dashed line). However, when corrections for RNA extraction and testis and body weight changes were applied 

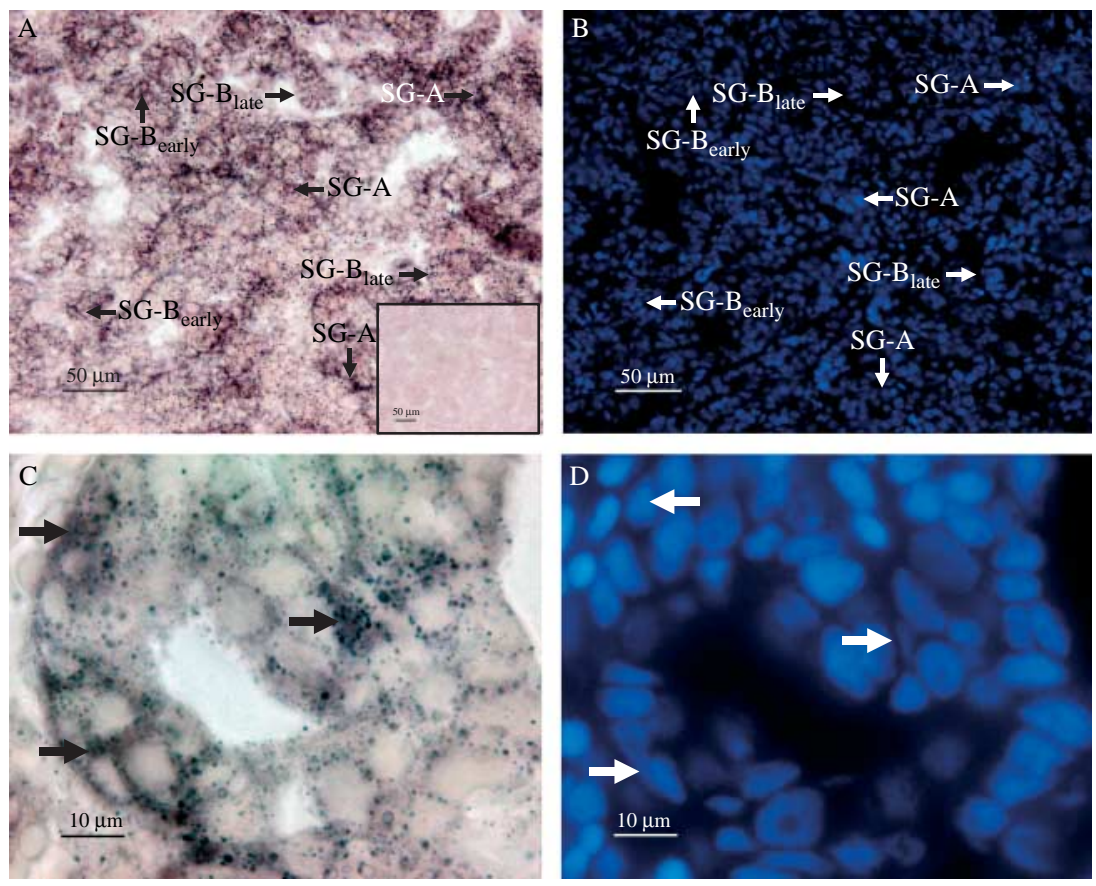

Figure 3 In situ hybridization of salmon pgr mRNA in testis from an NL-exposed male at the beginning of spermatogenesis, containing type $A$, early type $B$, and late type $B$ spermatogonia. The antisense cRNA probe (A) strongly labeled Sertoli cells contacting type A (SG-A) and early type B spermatogonia (SG-B $B_{\text {early }}$ ) that are recognized by the larger cell size and cysts containing single cells, pairs, or small groups of spermatogonia (B, DAPI-counterstained section). A weak label was found on Sertoli cells contacting late type B spermatogonia $\left(S G-B_{\text {late }}\right)$. Note that interstitial tissue remained unstained. A higher magnification (C) shows the signal in the cytoplasm of Sertoli cells that are recognized by the triangular or elongated shape of their nuclei (D, DAPI-counterstained section). Black arrows (C) indicate Sertoli cell cytoplasm. White arrows (D) indicate Sertoli cell nuclei. Inset in (A) showed the sense cRNA probe that did not result in specific staining. according to Kusakabe et al. (2006), the pattern of testicular pgr mRNA expression was similar to those of GSI and plasma DHP levels (Fig. 4G), i.e. a steady increase in pgr expression that followed the progress of germ cell development.

Grouping of the LL-exposed animals according to the stage of spermatogenesis resulted in patterns of plasma DHP and pgr mRNA expression levels (Fig. 4D, F, and H) that were very similar to those observed under NL conditions (Fig. 4C, E, and G). It seems, therefore, that for the changes in hormone level and its nuclear receptor, the developmental stage is a rather important parameter.

\section{Discussion}

The structural features of the cloned salmon pgr cDNA suggest that it encodes a member of the nuclear receptors family. These modular proteins are composed of a variable TAD at the $\mathrm{N}$-terminus, a highly conserved DBD, a hinge region, and a conserved LBD at the C-terminus (Evans 1988). The salmon Pgr protein shares structural features with Pgr proteins from other teleost species. For example, the highly conserved DBD contains cysteine residues, constituting the two zinc finger motifs, as well as the P box (GSCKV) and the D box (AGRND) sequences (Umesono \& Evans 1989), important regions for the recognition of Pgr target gene sequences, are all conserved in the salmon Pgr. The result of our comparative analysis of Pgr amino acid sequences was congruent with the phylogenetic relationship among the major vertebrate clades (Carroll 1988). This includes a proline-rich motif in the
$\mathrm{N}$-terminal domain of the human PGR, responsible for the interaction with the c-Src family of tyrosine kinases (Boonyaratanakornkit et al. 2001), which is absent in salmon, zebrafish, and eel (Todo et al. 2000, Ikeuchi et al. 2002, Chen et al. 2010), so that this particular region may not be available for Pgr-mediated Mos/MAPK activation in teleosts.

For many genes, ray-finned fish have two paralogous copies, whereas one ortholog is present in tetrapods (Wittbrodt et al. 1998). This is related to the teleostspecific genome duplication that occurred after the split of the Acipenseriformes and the Semionotiformes from the lineage leading to teleost fish, but before the divergence of Osteoglossiformes (Hoegg et al. 2004). In eel, two distinct pgr genes have been reported (Todo et al. 2000, Ikeuchi et al. 2002). However, experimental trials to isolate additional pgr cDNAs or in silico approaches to identify related sequences did not provide evidence for the existence of additional pgr-like genes or mRNA isoforms from one gene in zebrafish, medaka, Takifugu, Tetraodon, and stickleback (Chen et al. 2010, Hanna et al. 2010). Our results from the phylogenetic analysis indicate that salmon and zebrafish Pgr as well as eel Pgr1 form a clade separate from eel Pgr2. Thus, it is likely that the salmon genome lost the additional pgr gene. Our experimental evidence obtained by extensive RT-PCR with multiple primer sets and in silico approaches further support the existence of a single full-length pgr transcript produced from a single locus in the salmon genome.

In mammals, birds, and amphibians, progesterone is considered to be the main ligand for their PGRs. 
NL
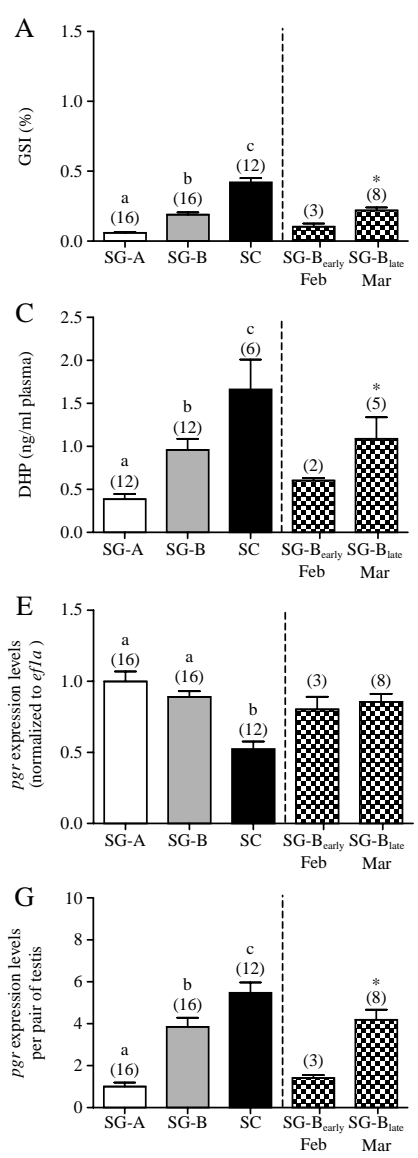

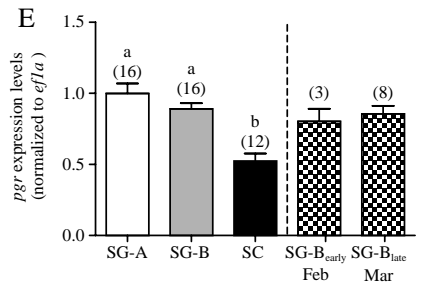

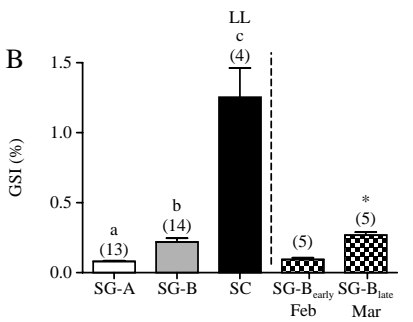
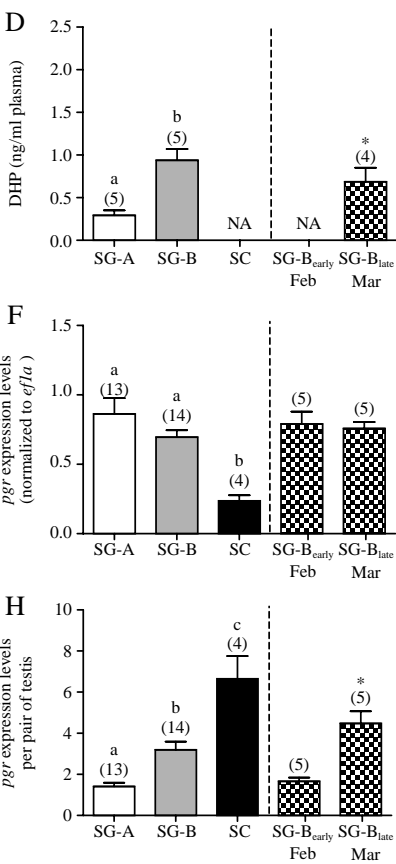

Figure 4 Changes in GSI (A and B), plasma DHP (C and D), and testicular pgr mRNA expression $(\mathrm{E}-\mathrm{H})$ levels in Atlantic salmon exposed to natural light ( $\mathrm{NL} ; \mathrm{A}, \mathrm{C}, \mathrm{E}$, and $\mathrm{G})$ or to additional constant light ( $L L ; B, D, F$, and $H$ ) during the onset of spermatogenesis. To the left of the dashed line, males were assigned to groups based on the testicular histology, with abbreviations indicating SG-A (type A spermatogonia), SG-B (type B spermatogonia), and SC (spermatocytes). Bars marked with different letters are significantly different between each other $(P<0.05)$. To the right of the dashed line, data are shown of males sampled in February that showed early type B spermatogonia (SG-B $B_{\text {early }}$ ) as the most advanced germ cell type in the testis, and of males sampled in March showing late type B spermatogonia (SG-B late $_{\text {le }}$ as the most developed advanced germ cell type; in February, all males in the SG-B stage showed early type B spermatogonia, while all males in the SG-B stage in March and April showed late type B spermatogonia. Asterisks indicate significant differences to the mean values of groups showing SG-A or SG-B $B_{\text {early }}(P<0.05)$. The number of animals per group is indicated between brackets above each column. NA, sufficient volumes of plasma samples were not available from some individuals.

In teleost fish, however, DHP is the main ligand for Pgrs (Ikeuchi et al. 2002, Chen et al. 2010). In this study, we demonstrated that the salmon pgr cDNA codes for a functional Pgr, which is able to transactivate target genes in a progestogen-dependent manner. Transactivation was progestogen specific, and DHP was the most effective steroid, supporting the view that DHP is the major native ligand for the salmon Pgr.
In contrast to the wide expression pattern of PGRs in mammals (Graham \& Clarke 1997), the salmon pgr has a less broad expression pattern, which has also been observed in zebrafish and eel (Ikeuchi et al. 2002, Chen et al. 2010). However, in all vertebrates, PGRs are expressed predominantly in the reproductive organ (Graham \& Clarke 1997, Wang et al. 2004, GonzálezMorán et al. 2008). Interestingly, pgr mRNA has a less broad expression pattern than the androgen receptor in male teleosts (de Waal et al. 2008), although both receptor types were created from a 3-ketogonadal steroid receptor by the third genome duplication during vertebrate evolution (Thornton 2001). However, androgens have multiple functions in the morphological specification of the male phenotype that has evolved also in the teleost lineage, while Pgr-mediated functions seem restricted to reproductive physiology (Ogino et al. 2004). Ohno (1970) proposed that gene duplications facilitate the functional diversification of genes and generates the developmental and morphological complexity during evolution. This difference in functional diversification between androgen receptor and PGR may explain the presence of two subtypes of pgr genes only in eel, while distinct paralogous copies of androgen receptors have been identified in several species (Ogino et al. 2009).

The localization of PGRs in the vertebrate testis provided different results. Studies on boar, rat, and dog reported PGR protein localization to germ cells (Galena et al. 1974, Sirivaidyapong et al. 2001, Kohler et al. 2007). In the human testis, also Sertoli and Leydig cells were PGR-positive (Shah et al. 2005). However, a much more restricted distribution, namely to peritubular cells and to Leydig cells of human and non-human primate testes, was reported in a study using four different antibodies (Luetjens et al. 2006). In Japanese eel, pgr1 mRNA was expressed in germ cells, Sertoli cells, and interstitial cells of testis, whereas pgr2 mRNA was detected, by RT-PCR, only in germ cells (Miura et al. 2006). In zebrafish, we found pgr mRNA expression in Leydig and Sertoli cells only (Chen et al. 2010), while Hanna et al. (2010) reported Pgr protein expression in spermatogonia and spermatocytes. In this study, we found a strong in situ hybridization signal of salmon $p g r$ mRNA in Sertoli cells surrounding type A and early type B spermatogonia, while Sertoli cells contacting larger clones with further differentiated germ cells (e.g. late type B spermatogonia) were less intensely/not stained. In Japanese eel, the molecular mechanism underlying DHPmediated stimulation of spermatogenesis involved elevated expression of $11 \beta$-hydroxysteroid dehydrogenase and trypsinogen in Leydig and Sertoli cells respectively (Ozaki et al. 2006, Miura et al. 2009). The Sertoli cell expression that we report is consistent with the presence of Pgr in testicular somatic cells in vertebrates, but we could not detect pgr mRNA in Leydig cells. This is possibly related to the fact that our study was restricted to the initiation of spermatogenesis, a period during which 
Leydig cell activity is still relatively low and plasma androgen levels are far away from their annual maximum values in the spawning season (Mayer et al. 1990).

In seasonally breeding teleosts, the size and cellular composition of the testis change considerably, which involves proliferation of germ cells and of somatic cells (Schulz et al. 2010). Moreover, testis growth is accompanied by a significant change in the amount of total RNA per testes (Kusakabe et al. 2002), and germ cell proliferation greatly exceeds Sertoli cell proliferation (see below), so that the proportion of somatic cell transcripts in the total testis mRNA becomes underrepresented when spermatogenesis progresses. Based on this point of view, we understand the decrease in testicular pgr expression levels that is associated with the appearance of spermatocytes when normalizing the results to ef $\alpha$ only (Fig. $4 \mathrm{E}$ and F) as reflecting the dilution of Sertoli cell-derived mRNAs during germ cell proliferation.

Hence, a manner to report qPCR data for relative gene expression should be developed for an alternative presentation of the testicular expression data. Kusakabe et al. (2006) described an approach that incorporated RNA yield ( $\mu$ g RNA recovered per mg tissue extracted) and gonad and body weight changes into the calculation of the relative level of target gene expression, in addition to normalization to ef $1 \alpha$ mRNA levels. We have applied the correction for testis weight based on the following reasoning. In situ hybridization showed that pgr mRNA is restricted to Sertoli cells. The seasonal spermatogenesis/ testis growth is associated with both Sertoli and germ cell proliferation in fish (Schulz et al. 2010), and Sertoli cell proliferation mainly occurs during the mitotic expansion of the spermatogonial population (e.g. Schulz et al. 2005). However, germ cell proliferation greatly exceeds Sertoli cell proliferation, so that the germ/Sertoli cell ratio increases from 0.5 to 0.8 in cysts containing single type A spermatogonia to $\sim 100-170$ in cysts containing spermatids (Billard 1969, Matta et al. 2002, Schulz et al. 2005, Leal et al. 2009). Data on germ cell and Sertoli cell proliferation are not available for salmon, but histological analysis of salmonid testes suggests that germ cell proliferation greatly exceeds Sertoli cell proliferation also in salmonids (e.g. Billard 1983, Schulz 1984). Hence, the cellular composition of maturing testis changes such that Sertoli cell-derived mRNAs become progressively diluted by germ cell mRNAs up to a factor of $\sim 125$ (i.e. 100/0.8). Also the GSI increases $\sim 100$ fold in males in different seasonally reproducing species (e.g. Schulz 1984, Almeida et al. 2008), again mainly reflecting an increase in germ cell number. Therefore, testis mass changes are suitable to estimate the dilution of Sertoli cell-derived mRNAs, in particular up until the end of meiosis, since spermatogonia and spermatocytes contain normal and high amounts of mRNAs respectively while this is different once the relative masses of spermatids and spermatozoa increase, since haploid cells contain little mRNA. However, except for two fish in the final sampling showing the first spermatids, these later maturational stages were not present in this study. The correction for body weight has been applied to take into account interindividual, isometric differences in testis weight. When calculated according to Kusakabe et al. (2006), pgr mRNA expression levels increased progressively during early spermatogenesis (Fig. 4G and $\mathrm{H})$. Since in situ hybridization results indicated that expression of pgr mRNA was most prominent in Sertoli cells contacting type A and early type B spermatogonia, we conclude that the progressive increase in testicular pgr mRNA levels reflects the increased number of new spermatogonial cysts formed during the onset of testis growth, or more specifically, the increased number of Sertoli cells enveloping the newly formed type A and early type B spermatogonia.

One of the aims of this study was to investigate whether DHP, via a Pgr-mediated pathway, could participate in stimulating early spermatogenesis, by examining changes in pgr mRNA expression and plasma DHP during the onset of puberty in Atlantic salmon. A function of DHP during early spermatogenesis was first suggested by Dépêche \& Sire (1982), who reported that rainbow trout testis tissue produced DHP from $17 \alpha(\mathrm{OH}) \mathrm{P}_{4}$ when testis growth began with the start of rapid spermatogonial proliferation. Using a primary testis tissue culture system, it was further demonstrated that DHP induced spermatogonial DNA synthesis in Japanese huchen and eel (Amer et al. 2001, Miura et al. 2006). In this study, analyzing samples collected from animals during the early spermatogenic period, we observed that DHP plasma levels increased significantly first in fish, where the testes contained type B spermatogonia, compared with testes containing type A spermatogonia. Interestingly, this increase occurred in samples collected in March, but not in February, indicating that the transition from early type B to late type B spermatogonia that we have recorded histologically during this period is associated with the increased DHP plasma levels. Since our in situ hybridization localized pgr mRNA expression to Sertoli cells, we can assume a Sertoli cell-mediated effect of DHP on germ cell development, a situation that also characterizes androgen effects on spermatogenesis. Hence, it is possible that DHP, via a Pgr-mediated pathway, participated in stimulating the transition to the rapid mode of proliferation typical for the late type $B$ spermatogonia.

In male salmonid fish, plasma DHP levels increased with the appearance of meiotic cells in the testis of Japanese huchen, Hucho perryi (Amer et al. 2001), and rainbow trout, Oncorhynchus mykiss (Scott \& Sumpter 1989). This is in agreement with this study, where we found a significant increase in plasma DHP levels from stage SG-B to stage SC in Atlantic salmon, suggesting that DHP may be functionally related to the initiation of meiosis as well, as had been demonstrated 
experimentally for Japanese eel (Miura et al. 2006). However, considering our in situ hybridization results that Sertoli cells contacting larger clones with further differentiated germ cells were less intensely/not stained, it seems that once DHP participated in stimulating the further development of early type B spermatogonia, pgr mRNA expression may become down-regulated in the Sertoli cells now contacting late type B spermatogonia. Still, without data on the half-life time of Pgr protein, we cannot exclude that Pgr protein persists longer than its mRNA. Taken together, the present data are not conclusive as regards a potential function of DHP/Pgr in meiosis, and other experimental approaches will be required to address this question.

A possible explanation for the observed increase in plasma DHP levels that were associated with the transition from early to late type B spermatogonia and again to spermatocytes is an observation made in rainbow trout, where the enzyme 20 $\beta$-hydroxysteroid dehydrogenase, converting $17 \alpha(\mathrm{OH}) \mathrm{P}_{4}$ to DHP, was localized to spermatogonia (Vizziano et al. 1996). Hence, the increasing number of spermatogonia typically observed at the start of testis growth might pave the way, by providing ligand for Pgr present in Sertoli cells contacting early spermatogonia, for stimulating germ cell development toward meiosis. Down-regulating pgr mRNA expression in Sertoli cells that envelope more advanced germ cell stages and cessation of the production of new spermatogonial cysts may be the two aspects contributing to terminate the DHP/Pgr-driven regulatory loop that we postulate to operate during the rapid spermatogonial proliferation phase in Atlantic salmon.

In summary, we have cloned a single cDNA coding for a Pgr in the Atlantic salmon; there are no indications suggesting that another pgr gene is present in the salmon genome. Pharmacological characterization, cellular localization, and quantification of pgr mRNA in salmon testis in relation to other reproductive parameters suggest that the salmon Pgr, which is expressed in Sertoli cells and best activated by its natural ligand (DHP), may be involved in the regulation of early spermatogenesis, particularly the proliferation of type B spermatogonia. Additional studies using models allowing more direct experimental approaches, e.g. testis tissue culture studies, are needed to obtain further information on the roles of DHP/Pgr in the regulation of spermatogenesis.

\section{Materials and Methods}

\section{Maintenance, photoperiod treatment, and sampling of fish}

Previously immature, two sea-winter old salmon had been kept in sea cages at the Institute of Marine Research (Matre, Norway; $61^{\circ} \mathrm{N}$ ) under $\mathrm{NL}$ conditions for 19 months until the start of the trial. An initial control sample was collected on 8 January. Starting on 1 February, half of the animals were exposed to additional LL, while the other half remained under $\mathrm{NL}$ conditions. Samples were then collected at four time points: 18 February, 19 March, 25 April, and 11 June. In June, maturation was clearly visible in all males of the NL group, and the experiment was terminated.

For tissue and blood sampling, the fish were netted from the sea cages, immediately anesthetized with 6 ppt metomidate (Syndel, Victoria, BC, Canada), and weighed (total body weight); blood was collected in heparinized syringes from the caudal veins, and gonads were excised and weighed. The GSI was calculated as: GSI $(\%)=$ gonad weight $(\mathrm{g}) \times 100 /$ total body weight (g). Testis tissue samples were either shock frozen in liquid nitrogen and then stored at $-80{ }^{\circ} \mathrm{C}$ for gene expression analysis or fixed for different purposes.

\section{Testis histology and sex steroid quantification}

For routine histological analysis, a testis tissue fragment was fixed in phosphate buffered $4 \% \mathrm{~m} / \mathrm{v}$ paraformaldehyde and $2 \%$ $\mathrm{v} / \mathrm{v}$ acetic acid, dehydrated, and embedded in paraffin wax, according to conventional techniques; $5 \mu \mathrm{m}$ sections were stained with hematoxylin and eosin.

Stages of spermatogenesis were determined by identifying the most advanced germ cell generation, using criteria and a terminology that can be applied to male germ cells in all vertebrates (Schulz et al. 2010). The animals were assigned to one of the three following stages of spermatogenesis. In stage SG-A, the testes contained only type A spermatogonia that showed a large nucleus ( $\sim 10 \mu \mathrm{m}$; Supplementary Figure 1A, see section on supplementary data given at the end of this article) with little heterochromatin and one or two prominent nucleoli. This largest type of spermatogonia often occurred as single cells in contact with one or two Sertoli cells. In stage SG-B, type B spermatogonia were present in addition to type A spermatogonia. Early generations of type B spermatogonia were present in pairs or small groups and had a smaller nucleus ( $\sim 7 \mu \mathrm{m}$; Supplementary Figure $1 \mathrm{~B})$ that stained more intensely with hematoxylin. Late type B spermatogonia occurred in larger groups and showed an increased amount of heterochromatin speckles distributed over, in general, more darkly stained nucleus (Supplementary Figure 1C), and the cytoplasmic area stained more intensely with eosin than in the previous germ cell generations. In stage SC, spermatocytes were present, which occurred in large groups and were characterized by the presence of darkly staining meiotic chromosomes at different stages of condensation during the first meiotic prophase (Supplementary Figure 1D). In two out of the 12 animals found in stage SC, spermatids were found as well (Supplementary Figure 1D).

Aliquots of blood plasma were obtained by centrifugation at $3000 \mathrm{~g}$ at $4{ }^{\circ} \mathrm{C}$ for $10 \mathrm{~min}$ and stored at $-80^{\circ} \mathrm{C}$ until analyzed for DHP. Since low levels of DHP were expected, $500 \mu \mathrm{l}$ plasma sample were extracted with $5 \mathrm{ml}$ diethyl ether, and the ether was decanted. This procedure was repeated twice, and the ether fractions were combined and evaporated to dryness. The residue was dissolved in $5 \mathrm{ml}$ of $70 \%(\mathrm{v} / \mathrm{v})$ methanol and stored at $-20{ }^{\circ} \mathrm{C}$ overnight for defatting. After centrifugation at $3000 \mathrm{~g}$ at $4{ }^{\circ} \mathrm{C}$ for $10 \mathrm{~min}$, the methanol-water supernatant was decanted, evaporated to dryness, and the dry residue was 
dissolved in $125 \mu \mathrm{l}$ RIA buffer and assayed as described previously (Schulz et al. 1994). In some cases, the available volume of plasma was not sufficient, so that the number of samples analyzed for DHP plasma levels was smaller than for pgr mRNA expression.

\section{Cloning and sequence analysis of salmon pgr cDNA}

Total RNA was extracted from adult salmon ovary using the FastRNA Pro Green kit (MP Biomedicals, Solon, OH, USA). Poly(A)-rich salmon ovary RNA was isolated using Dynabeadsoligo $\mathrm{dT}_{25}$ (Dynal A.S., Oslo, Norway) and reverse transcribed to $5^{\prime}$ - and 3'-RACE ready cDNA using a SMART RACE CDNA amplification kit (Clontech) following the manufacturer's instructions.

To obtain a partial salmon pgr cDNA sequence, $2 \mu \mathrm{l}$ random hexamer-primed salmon ovary cDNA were used as template in a PCR with primer set 2699 and 2700 (Supplementary Table 1, see section on supplementary data given at the end of this article), corresponding to highly conserved amino acid sequences found in known PGRs. The PCR was carried out in a $50 \mu \mathrm{l}$ volume using the Advantage 2 PCR system (Clontech) in a Perkin-Elmer 2400 Thermal Cycler (Applied Biosystems, Foster City, CA, USA) under the following cycling conditions: denaturation at $94{ }^{\circ} \mathrm{C}$ for $10 \mathrm{~s}$, followed by 35 cycles of $94{ }^{\circ} \mathrm{C}$ for $10 \mathrm{~s}, 55^{\circ} \mathrm{C}$ for $10 \mathrm{~s}, 68^{\circ} \mathrm{C}$ for $1 \mathrm{~min}$. DNA fragments were subcloned into pcDNA3.1/V5-His-TOPO vector (Invitrogen), and plasmid DNA of two clones was prepared for DNA sequence analysis.

To isolate the $5^{\prime}$ - and $3^{\prime}$-ends of the salmon pgr cDNA, genespecific primers (2722 and 2720; Supplementary Table 1) based on the consensus nucleotide sequence of the abovementioned two clones were used in combination with a universal primer mix (UPM) for $5^{\prime}$ - and $3^{\prime}$-RACE respectively. These initial $5^{\prime}$ - and $3^{\prime}$-RACE products were then used for nested PCR amplifications using gene-specific nested primers (2721 and 2723; Supplementary Table 1) respectively, in combination with a nested universal primer (NUP). To obtain more sequence information at the $3^{\prime}$-end of the salmon $p g r$, an additional $3^{\prime}$-RACE was performed using the gene-specific primers 2767 and 2768 (Supplementary Table 1) in combination with UPM and NUP respectively. Both the UPM and NUP were supplied with the SMART RACE cDNA amplification kit (Clontech). All RACE reactions were carried out according to the manufacturer's instructions in a Perkin-Elmer 2400 Thermal Cycler (Applied Biosystems) using Advantage 2 polymerase (Clontech). RACE products were subcloned into pcDNA3.1/N5-His-TOPO vector (Invitrogen).

The ORF of the salmon pgr was PCR amplified using primers 2794 and 2796 (Supplementary Table 1), subcloned into pcDNA3.1/V5-His-TOPO vector, and checked for the correct orientation by DNA sequence analysis. DNA sequence analyses were performed using dye terminator cycle sequencing chemistry (Applied Biosystems).

\section{Phylogenetic analysis}

After obtaining the salmon pgr cDNA sequence, a BLAST homology search was performed. The alignment of multiple nuclear PGR sequences were performed using the MegAlign program of the Lasergene software package (DNASTAR, Inc., Madison, WI, USA) with the Clustal V (PAM 250) algorithm, and percentage identities were calculated. We only selected (deduced) PGR amino acid sequences from studies that experimentally demonstrated progestogens binding to the receptors (see Supplementary Table 2 for the respective GenBank accession numbers). The phylogenetic tree was constructed using the neighbor-joining method with a bootstrap value of 1000 trials for each position and rooted by two types of Atlantic salmon androgen receptor (data not shown).

\section{Transactivation assays for salmon Pgr}

Receptor activation was measured using a reporter gene assay as described previously (Chen et al. 2010). Briefly, HEK 293T cells were seeded in $10 \mathrm{~cm}$ dishes in DMEM supplemented with $10 \% \mathrm{v} / \mathrm{v}$ fetal bovine serum (FBS), glutamine, and penicillin/streptomycin (Gibco) at $37{ }^{\circ} \mathrm{C}$ in a $5 \% \quad \mathrm{CO}_{2}$ incubator. After $24 \mathrm{~h}$, the cells were co-transfected using a standard calcium phosphate precipitation method with $1 \mu \mathrm{g}$ of the salmon pgr expression plasmid and $7 \mu$ g of pGL3-MMTVLuc plasmid. After 5-6 h, the transfected cells were transferred to 24-well plates. The next day, the medium was replaced by transactivation assay medium (DMEM without phenol red, supplemented with $0.2 \% \mathrm{v} / \mathrm{v}$ charcoal-stripped FBS, glutamine, and non-essential amino acids) containing different steroids (in duplicate) with final concentrations ranging between $0.1 \mathrm{nM}$ and $10 \mu \mathrm{M}$. After incubation at $37^{\circ} \mathrm{C}$ for $24-36 \mathrm{~h}$, the cells were harvested in lysis mix and stored at $-80^{\circ} \mathrm{C}$. Luminescence was measured in a Packard TopCount NXT luminometer (Perkin Elmer Life Sciences, Meriden, CT, USA). Each compound was tested in three independent experiments using cells from different transfections.

The following steroids were used in this study: DHP, 20ß-S, $\mathrm{P}_{4}, 17 \alpha(\mathrm{OH}) \mathrm{P}_{4}$, testosterone, 11-KT, $\mathrm{E}_{2}$, cortisol, and the synthetic progestin promegestone (R5020). All steroids were purchased from Sigma-Aldrich (Zwijndrecht, The Netherlands).

\section{Localization and quantification of pgr expression}

Localization of receptor expression by in situ hybridization was done as described previously (Chen et al. 2010), using $10 \mu \mathrm{m}$ cryosections prepared from paraformaldehyde-fixed testis tissue from fish sampled during the onset of spermatogenesis. Cell nuclei were visualized with DAPI counterstaining (Vectashield with DAPI; Vector Laboratories, Burlingame, CA, USA). Specific primers (3168 and 3198; Supplementary Table 1) were designed to amplify a salmon pgr cDNA fragment for sense and antisense digoxigenin-labeled cRNA probe synthesis.

To assess the tissue specificity of pgr expression in Atlantic salmon, brain, gill, head kidney (including interrenal cells), heart, intestine, kidney, liver, spleen, muscle, ovary, pituitary, and stomach tissue samples were collected from three previtellogenic females in January, and testis tissue samples were collected from three immature fish in January, and used 
for RNA isolation and cDNA synthesis, as described previously (Andersson et al. 2009).

Primers 2831 and 2832 (Supplementary Table 1) were designed to detect salmon pgr using quantitative real-time PCR (qPCR). The specificity and efficiency of this pgr primer set were tested with qPCR on serial dilutions of salmon testis cDNA as described elsewhere (Vischer et al. 2003). Atlantic salmon ef1 $\alpha$ was used as reference gene as described in detail previously (Andersson et al. 2009); no significant differences in expression levels were found in the testis samples analyzed (Supplementary Figure 5). All qPCR were performed in $20 \mu \mathrm{l}$ volume, and $C_{\mathrm{t}}$ values were determined in a $7900 \mathrm{HT}$ Real-Time PCR System (Applied Biosystems) using default settings. To calculate gene expression data, the $\Delta \Delta C_{\mathrm{t}}$ method was used, as described in detail previously (Bogerd et al. 2001).

The expression levels in the different salmon tissues were normalized to ef $1 \alpha$ mRNA levels and are shown relative to the tissue showing the highest level of expression (immature testis tissue), which was set to 1. Expression levels in testis samples were calculated in two ways: normalized to ef $1 \alpha$ mRNA only (see Fig. 4E and F) and normalized to ef $1 \alpha$ mRNA and corrected according to Kusakabe et al. (2006) see Fig. 4G and $\mathrm{H}$ : pgr expression levels $=(q P C R$ value $/$ ef $1 \alpha$ value $) \times($ total $R N A$ amount extracted/tissue weight for RNA extraction) $\times$ (testis weight/body weight). The results are shown relative to immature testis tissue (i.e. stage SG-A), which was set to 1.

\section{Statistical analysis}

Analyses of GSI, DHP plasma levels, and pgr expression data were carried out on groups that were defined according to the histological analysis of testis development (stages SG-A, SG-B early or late, and SC) and exposure to NL or LL. Data were subjected to ANOVA, followed by a Tukey's unequal N HSD test to identify differences among groups. Differences between testes in the SG-A and SG-B stages, collected in a given month, were analyzed using a Student's t-test. In all case, significance was accepted at $P<0.05$. Data are presented as the mean \pm s.E.M.

\section{Supplementary data}

This is linked to the online version of the paper at http://dx.doi. org/10.1530/REP-10-0224.

\section{Declaration of interest}

The authors declare that there is no conflict of interest that could be perceived as prejudicing the impartiality of the research reported.

\section{Funding}

This work was supported by the Norwegian Research Council (grant number 159662/S40 to E Andersson, G L Taranger, J Bogerd, and R W Schulz) and China Scholarship Council (grant number 2007101952 to S X Chen).

\section{Acknowledgements}

The authors thank Wytske van Dijk, Joke Granneman, and Natasja E Schoonen (all from the Division Endocrinology and Metabolism) for technical support. Rune Male from the Department Molecular Biology, University of Bergen, Bergen, Norway, is acknowledged for support during accessing the Atlantic salmon genome database.

\section{References}

Almeida FFL, Kristoffersen C, Taranger GL \& Schulz RW 2008 Spermatogenesis in Atlantic cod (Gadus morhua): a novel model of cystic germ cell development. Biology of Reproduction 78 27-34. (doi:10.1095/biolreprod.107.063669)

Amer MA, Miura T, Miura C \& Yamauchi K 2001 Involvement of sex steroid hormones in the early stages of spermatogenesis in Japanese huchen (Hucho perryi). Biology of Reproduction 65 1057-1066. (doi:10.1095/ biolreprod65.4.1057)

Andersson E, Nijenhuis W, Male R, Swanson P, Bogerd J, Taranger GL \& Schulz RW 2009 Pharmacological characterization, localization and quantification of expression of gonadotropin receptors in Atlantic salmon (Salmo salar L.) ovaries. General and Comparative Endocrinology 163 329-339. (doi:10.1016/j.ygcen.2009.05.001)

Baynes SM \& Scott AP 1985 Seasonal variations in parameters of milt production and in plasma concentration of sex steroids of male rainbow trout (Salmo gairdneri). General and Comparative Endocrinology 57 150-160. (doi:10.1016/0016-6480(85)90211-4)

Billard R 1969 La spermatogenèse de Poecilia reticulata I. Estimation du nombre de générations goniales et rendement de la spermatogenèse. Annales de Biologie Animale - Biochimie et Biophysique 9 251-271. (doi:10.1051/rnd:19690208)

Billard R 1983 A quantitative analysis of spermatogenesis in the trout, Salmo trutta fario. Cell and Tissue Research 230 495-502. (doi:10.1007/ BF00216195)

Bogerd J, Blomenrohr M, Andersson E, van der Putten HHAGM, Tensen CP, Vischer HF, Granneman JC, Janssen-Dommerholt C, Goos HJTh \& Schulz RW 2001 Discrepancy between molecular structure and ligand selectivity of a testicular follicle-stimulating hormone receptor of the African catfish (Clarias gariepinus). Biology of Reproduction 64 1633-1643. (doi:10.1095/biolreprod64.6.1633)

Boonyaratanakornkit V, Scott MP, Ribon V, Sherman L, Anderson SM, Maller JL, Miller WT \& Edwards DP 2001 Progesterone receptor contains a proline-rich motif that directly interacts with $\mathrm{SH} 3$ domains and activates C-Src family of tyrosine kinases. Molecular Cell 8 269-280. (doi:10.1016/S1097-2765(01)00304-5)

Carroll RL 1988 Vertebrate Paleontology and Evolution. New York: WH Freeman and Company.

Chen SX, Bogerd J, García-López A, de Jonge H, de Waal PP, Hong WS \& Schulz RW 2010 Molecular cloning and functional characterization of a zebrafish nuclear progesterone receptor. Biology of Reproduction 82 171-181. (doi:10.1095/biolreprod.109.077644)

Dépéche J \& Sire O 1982 In vitro metabolism of progesterone and $17 \alpha-$ hydroxyprogesterone in the testis of the rainbow trout, Salmo gairdneri Rich., at different stages of spermatogenesis. Reproduction, Nutrition, Development 22 427-438. (doi:10.1051/rnd:19820314)

Evans RM 1988 The steroid and thyroid hormone receptor superfamily. Science 240 889-895. (doi:10.1126/science.3283939)

Galena HJ, Pillai AK \& Terner C 1974 Progesterone and androgen receptors in non-flagellate germ cells of the rat testis. Journal of Endocrinology 63 223-237. (doi:10.1677/joe.0.0630223)

González-Morán MG, Guerra-Araiza C, Campos MG \& Camacho-Arroyo I 2008 Histological and sex steroid hormone receptor changes in testes of immature, mature, and aged chickens. Domestic Animal Endocrinology 35 371-379. (doi:10.1016/j.domaniend.2008.08.001)

Graham JD \& Clarke CL 1997 Physiological action of progesterone in target tissues. Endocrine Reviews 18 502-519. (doi:10.1210/er.18.4.502) 
Hanna RN \& Zhu Y 2009 Expression of membrane progestin receptors in zebrafish (Danio rerio) oocytes, testis and pituitary. General and Comparative Endocrinology 161 153-157. (doi:10.1016/j.ygcen.2008. 10.006)

Hanna RN, Daly SC, Pang Y, Anglade I, Kah O, Thomas P \& Zhu Y 2010 Characterization and expression of the nuclear progestin receptor in zebrafish gonads and brain. Biology of Reproduction 82 112-122. (doi:10.1095/biolreprod.109.078527)

Hoegg S, Brinkmann H, Taylor JS \& Meyer A 2004 Phylogenetic timing of the fish-specific genome duplication correlates with the diversification of teleost fish. Journal of Molecular Evolution 59 190-203. (doi:10.1007/ s00239-004-2613-z)

Ikeuchi T, Todo T, Kobayashi T \& Nagahama Y 2002 A novel progesterone receptor subtype in the Japanese eel, Anguilla japonica. FEBS Letters $\mathbf{5 1 0}$ 77-82. (doi:10.1016/S0014-5793(01)03220-3)

Kohler C, Riesenbeck A \& Hoffmann B 2007 Age-dependent expression and localization of the progesterone receptor in the boar testis. Reproduction in Domestic Animals 42 1-5. (doi:10.1111/j.1439-0531.2006.00661.x)

Kusakabe M, Kobayashi T, Todo T, Lokman PM, Nagahama Y \& Young G 2002 Molecular cloning and expression during spermatogenesis of a cDNA encoding testicular $11 \beta$-hydroxylase $(\mathrm{P} 45011 \beta)$ in rainbow trout (Oncorhynchus mykiss). Molecular Reproduction and Development 62 456-469. (doi:10.1002/mrd.10145)

Kusakabe M, Nakamura I, Evans J, Swanson P \& Young G 2006 Changes in mRNAs encoding steroidogenic acute regulatory protein, steroidogenic enzymes and receptors for gonadotropins during spermatogenesis in rainbow trout testes. Journal of Endocrinology 189 541-554. (doi:10. 1677/joe.1.06684)

Leal MC, Cardoso ER, Nóbrega RH, Batlouni SR, Bogerd J, França LR \& Schulz RW 2009 Histological and stereological evaluation of zebrafish (Danio rerio) spermatogenesis with an emphasis on spermatogonial generations. Biology of Reproduction 81 177-187. (doi:10.1095/ biolreprod.109.076299)

Luetjens CM, Didolkar A, Kliesch S, Paulus W, Jeibmann A, Bocker W, Nieschlag E \& Simoni M 2006 Tissue expression of the nuclear progesterone receptor in male non-human primates and men. Journal of Endocrinology 189 529-539. (doi:10.1677/joe.1.06348)

Matta SL, Vilela DA, Godinho HP \& Franca LR 2002 The goitrogen 6-n-propyl2-thiouracil (PTU) given during testis development increases Sertoli and germ cell numbers per cyst in fish: the tilapia (Oreochromis niloticus) model. Endocrinology 143 970-978. (doi:10.1210/en.143.3.970)

Mayer I, Lundqvist H, Berglund I, Schmitz M, Schulz R \& Borg B 1990 Seasonal endocrine changes in Baltic salmon, Salmo salar, immature parr and mature male parr. I. Plasma levels of five androgens, 17-hydroxy$20 \beta$-dihydroprogesterone, and $17 \beta$-estradiol. Canadian Journal of Zoology 68 1360-1365. (doi:10.1139/z90-203)

Miura T, Yamauchi K, Takahashi H \& Nagahama Y 1992 The role of hormones in the acquisition of sperm motility in salmonid fish. Journal of Experimental Zoology 261 359-363. (doi:10.1002/jez.1402610316)

Miura T, Higuchi M, Ozaki Y, Ohta T \& Miura C 2006 Progestin is an essential factor for the initiation of the meiosis in spermatogenetic cells of the eel. PNAS 103 7333-7338. (doi:10.1073/pnas.0508419103)

Miura C, Ohta T, Ozaki Y, Tanaka H \& Miura T 2009 Trypsin is a multifunctional factor in spermatogenesis. PNAS 106 20972-20977. (doi:10.1073/pnas.0907631106)

Ogino Y, Katoh H \& Yamada G 2004 Androgen dependent development of a modified anal fin, gonopodium, as a model to understand the mechanism of secondary sexual character expression in vertebrates. FEBS Letters 575 119-126. (doi:10.1016/j.febslet.2004.08.046)

Ogino Y, Katoh H, Kuraku S \& Yamada G 2009 Evolutionary history and functional characterization of androgen receptor genes in jawed vertebrates. Endocrinology 150 5415-5427. (doi:10.1210/en.2009-0523)

Ohno S 1970 Evolution of Gene Duplication. New York: Springer Verlag.

Ozaki Y, Higuchi M, Miura C, Yamaguchi S, Tozawa Y \& Miura T 2006 Roles of $11 \beta$-hydroxysteroid dehydrogenase in fish spermatogenesis. Endocrinology 147 5139-5146. (doi:10.1210/en.2006-0391)

Schulz R 1984 Serum levels of 11-oxotestosterone in male and $17 \beta$-estradiol in female rainbow trout (Salmo gairdneri) during the first reproductive cycle. General and Comparative Endocrinology $\mathbf{5 6}$ 111-120. (doi:10.1016/0016-6480(84)90067-4)

Schulz RW, van der Corput L, Janssen-Dommerholt C \& Goos HJTh 1994 Sexual steroids during puberty in male African catfish (Clarias gariepinus): serum levels and gonadotropin-stimulated testicular secretion in vitro. Journal of Comparative Physiology. B, Biochemical, Systemic, and Environmental Physiology 164 195-205. (doi:10.1007/BF00354080)

Schulz RW, Menting S, Bogerd J, de Françac LR, Vilela DAR \& Godinho HP 2005 Sertoli cell proliferation in the adult testis: evidence from two fish species belonging to different orders. Biology of Reproduction 73 891-898. (doi:10.1095/biolreprod.105.039891)

Schulz RW, de França LR, Lareyre JJ, LeGac F, Chiarini-Garciac H, Nobrega RH \& Miura T 2010 Spermatogenesis in fish. General and Comparative Endocrinology 165 390-411. (doi:10.1016/j.ygcen. 2009.02.013)

Scott AP \& Sumpter JP 1989 Seasonal variations in testicular germ cell stages and in plasma concentrations of sex steroids in male rainbow trout (Salmo gairdneri) maturing at 2 years old. General and Comparative Endocrinology 73 46-58. (doi:10.1016/0016-6480(89)90054-3)

Shah C, Modi D, Sachdeva G, Gadkar S \& Puri C 2005 Coexistence of intracellular and membrane-bound progesterone receptors in human testis. Journal of Clinical Endocrinology and Metabolism 90 474-483. (doi:10.1210/jc.2004-0793)

Sirivaidyapong S, Bevers MM, Gadella BM \& Colenbrander B 2001 Induction of the acrosome reaction in dog sperm cells is dependent on epididymal maturation: the generation of a functional progesterone receptor is involved. Molecular Reproduction and Development 58 451-459. (doi:10.1002/1098-2795(20010401)58:4<451::AID-MRD $14>3.0 . \mathrm{CO} ; 2-\mathrm{K})$

Thornton JW 2001 Evolution of vertebrate steroid receptors from an ancestral estrogen receptor by ligand exploitation and serial genome expansions. PNAS 98 5671-5676. (doi:10.1073/pnas.091553298)

Todo T, Ikeuchi T, Kobayashi T, Kajiura-Kobayashi H, Suzuki K, Yoshikuni M, Yamauchi K \& Nagahama Y 2000 Characterization of a testicular $17 \alpha, 20 \beta$-dihydroxy-4-pregnen-3-one (a spermiation-inducing steroid in fish) receptor from a teleost, Japanese eel (Anguilla japonica). FEBS Letters 465 12-17. (doi:10.1016/S0014-5793(99)01714-7)

Tubbs C \& Thomas P 2008 Functional characteristics of membrane progestin receptor alpha $(\mathrm{mPR} \alpha)$ subtypes: a review with new data showing $\mathrm{mPR} \alpha$ expression in seatrout sperm and its association with sperm motility. Steroids 73 935-941. (doi:10.1016/j.steroids.2007.12.022)

Ueda H, Kanbegawa A \& Nagahama Y 1985 Involvement of gonadotrophin and steroid hormones in spermiation in the amago salmon, Oncorhynchus rhodurus, and goldfish, Carassius auratus. General and Comparative Endocrinology 59 24-30. (doi:10.1016/0016-6480(85)90415-0)

Umesono K \& Evans RM 1989 Determinants of target gene specificity for steroid/thyroid hormone receptors. Cell 57 1139-1146. (doi:10.1016/ 0092-8674(89)90051-2)

Vischer HF, Teves AC, Ackermans JC, van Dijk W, Schulz RW \& Bogerd J 2003 Cloning and spatiotemporal expression of the follicle-stimulating hormone $\beta$ subunit complementary DNA in the African catfish (Clarias gariepinus). Biology of Reproduction 68 1324-1332. (doi:10.1095/ biolreprod.102.009985)

Vizziano D, LeGac F \& Fostier A 1996 Effect of $17 \beta$-estradiol, testosterone, and 11 -ketotestosterone on $17 \alpha, 20 \beta$-dihydroxy-4-pregnen-3-one production in the rainbow trout testis. General and Comparative Endocrinology 104 179-188. (doi:10.1006/gcen.1996.0160)

de Waal PP, Wang DS, Nijenhuis WA, Schulz RW \& Bogerd J 2008 Functional characterization and expression analysis of the androgen receptor in zebrafish (Danio rerio) testis. Reproduction 136 225-234. (doi:10.1530/REP-08-0055)

Wang L, Sanyal S, Oh DY, Kim J, Ju JW, Song K, Kim JW, Kwon HB \& Choi H 2004 Molecular cloning and characterization of an amphibian progesterone receptor from Rana dybowskii. General and Comparative Endocrinology 135 142-149. (doi:10.1016/j.ygcen.2003.08.003)

Wittbrodt J, Meyer A \& Schartl M 1998 More genes in fish? BioEssays: News and Reviews in Molecular, Cellular and Developmental Biology 20 511-515. (doi:10.1002/(SICI)1521-1878(199806)20:6<511::AID$\mathrm{BIES} 10>3.0 . \mathrm{CO} ; 2-3)$

Received 12 May 2010

First decision 25 June 2010

Revised manuscript received 9 December 2010

Accepted 18 January 2011 